\title{
Apolipoprotein E: non-cognitive symptoms and cognitive decline in late onset Alzheimer's disease
}

\author{
Clive Holmes, Raymond Levy, Declan M McLoughlin, John F Powell, Simon Lovestone
}

\begin{abstract}
Objectives-To determine the association between the $\varepsilon 2$ and $\varepsilon 4$ alleles of apolipoprotein $E$ (ApoE) and independent measures of cognitive decline and noncognitive symptomatology in late onset Alzheimer's disease.

Methods-The frequency of the $\varepsilon 2$ and $\varepsilon 4$ alleles of ApoE and their association with measures of cognitive decline and noncognitive symptomatology were assessed in a population based case register study of 164 patients with late onset Alzheimer's disease from the east Lambeth and south Southwark districts of south London.

Results-Analysis of a wide range of noncognitive symptoms against ApoE $\varepsilon 4$ genotype showed no significant association but a positive relation was found between ApoE $\varepsilon 2$ genotype and depressive symptomatology $(P=0.004)$. No relation was found between measurements of cognitive decline and the presence of the ApoE $\varepsilon 4$ allele. A trend for decreasing age at onset of 3 to 4 years in carriers of the ApoE $\varepsilon 4$ allele was found, confirming earlier studies.

Conclusion-Presence of the $\varepsilon 4$ allele of ApoE is associated with an earlier age at onset but does not seem to be related to either a more severe psychopathology or a more rapid progression of the illness. The $\varepsilon 2$ allele of ApoE is associated with depressive symptomatology in late onset Alzheimer's disease.
\end{abstract}

(F Neurol Neurosurg Psychiatry 1996;61:580-583)

Section of Old Age Psychiatry, Institute of Psychiatry C Holmes R Levy

D M McLoughlin

$S$ Lovestone

Department of Neurosciences, Institute of Psychiatry, De Crespigny Park, Denmark Hill, London SE5 8AF, UK

J F Powell

Correspondence to: Dr Clive Holmes, Section of Old Age Psychiatry, Institute of Psychiatry, De Crespigny Park, Denmark Hill, London SE5 8AF, UK.

Received 19 January 1996 and in revised form 22 June 1996 Accepted 21 August 1996
Keywords: Alzheimer's disease; apolipoprotein E; depression; cognitive decline

The importance of apolipoprotein $\mathrm{E}$ (ApoE) as a risk factor for familial and sporadic late onset Alzheimer's disease has been the focus of several investigations. ${ }^{12}$ Whereas some light has been shed on the relation between the ApoE genotype and the neuropathological features seen in Alzheimer's disease, ${ }^{3}$ information on its relation with the clinical features of Alzheimer's disease is largely confined to demographic variables such as age at onset. ${ }^{1}$

The association between the psychopathology of the disease and ApoE genotype has been relatively unexplored. What studies have been done have concentrated on measures of cognitive decline and its relation with the ApoE $\varepsilon 4$ allele. ${ }^{4-6}$ Whereas, by most defini- tions, ${ }^{7-9}$ Alzheimer's disease has at its core features of cognitive decline, there is clearly a large non-cognitive component which has major implications in the treatment and placement of patients.

The clinical features and progression of Alzheimer's disease may differ according to the setting in which the patient is found ${ }^{10}$ and case series of patients with dementia often select an atypical population. ${ }^{15}$ These findings emphasise the importance of population based cohort studies for clinicopathological and genetic correlation. However, even relatively large population studies ${ }^{24}$ result in few patients with Alzheimer's disease and hence there is also a need for a case register study representative of dementia subjects in the community.

\section{Methods}

\section{PATIENTS}

At the time of writing the next of kin of 200 patients from a present total of 424 on the Camberwell Case Register ${ }^{11} 12$ had consented to venepuncture and genetic testing. All patients were over 60 years of age at the onset of their illness. The case register is cumulative and was set up with the aim of identifying all persons drawn from a defined catchment area population who make contact with specialist agencies (psychiatric, geriatric, long stay care, or social services for the elderly) and are confirmed to have late life dementia. The area in question is composed of two south London districts-south Southwark and east Lambeth -and at the end of the 1991 census had a total population of 212650 of whom 27471 $(12.9 \%)$ were aged 65 and over. A one year incidence rate of $4 \cdot 1$ per 1000 population has previously been calculated ${ }^{11}$ which is similiar to that reported by two other surveys, in Finland ${ }^{13}$ and the United States, ${ }^{14}$ of all patients known to medical and social agencies.

Of these 200 patients, 107 fulfilled the National Institute of Neurological and Communicative Disorders and Stroke and Alzheimer Disease and Related Disorders (NINCDS-ADRDA) diagnostic criteria ${ }^{9}$ for probable and 57 for possible Alzheimer's disease and did not differ from the entire group on the register fulfilling these same criteria for age at interview, age at onset, duration of illness, sex distribution, or family history.

\section{CLINICAL ASSESSMENT}

The next of kin or main carer was interviewed in all cases by means of the CAMDEX infor- 
Table 1 Allele frequency of $\varepsilon 2, \varepsilon 3$, and $\varepsilon 4$ in probable $A D$, possible $A D$, and controls

\begin{tabular}{llllll}
\hline Population & No of patients & Mean age $(S D)$ & $\varepsilon 2$ Frequency & $\varepsilon 3$ Frequency & \&4 Frequency \\
\hline Probable AD & 107 & $82 \cdot 2(7 \cdot 2)$ & 0.023 & 0.677 & 0.300 \\
Possible AD & 57 & $80.9(5 \cdot 3)$ & 0.035 & 0.632 & 0.333 \\
Total AD & 164 & $81 \cdot 9(6 \cdot 6)$ & 0.027 & 0.662 & 0.311 \\
Controls $^{24}$ & 77 & $73 \cdot 2(6 \cdot 1)$ & 0.110 & 0.766 & 0.123 \\
\hline
\end{tabular}

$\mathrm{AD}=$ Alzheimer's disease.

mant questionnaire ${ }^{15}$ with additional questions from the Present behavioural examination ${ }^{16}$ and Stockton geriatric rating scale. ${ }^{17}$

All patients were cognitively assessed at initial presentation and subsequently at yearly intervals by means of the mini mental state examination (MMSE) ${ }^{18}$ and the Blessed dementia rating scale (BDRS). ${ }^{19}$

Yearly cognitive decline was calculated as the difference between the initial examination and that at first yearly follow up or as the mean rate of change over a two year period if a second yearly assessment had been made. In order not to underestimate rates of decline cases were selected with MMSE $\geqslant 5$ at initial examination as this represented the upper range of most predicted values of yearly cognitive decline. ${ }^{20}$

Non-cognitive variables were grouped in the register into five main categories and further subcategorised as follows: disorders of thought into persecutory and other delusions; disorders of perception into auditory, visual, and other hallucinatory phenomena plus misidentifications; disorders of mood into depressive and aggressive symptomatology; disorders of behaviour into wandering and stereotypical behaviours; and neurovegetative features into abnormalities of sleep and eating disorders. Each of the 12 subcategories was composed of five questions which were asked of the informant and the responses noted as symptom present or absent during the subject's illness. In addition, depressive features were assessed using the Cornell scale for depression in dementia. ${ }^{21}$

\section{APOE GENOTYPES}

Blood samples were collected on EDTA and stored at $-70^{\circ} \mathrm{C}$ until assayed. ApoE genotyping was carried out using one stage polymerase chain reaction followed by restriction enzyme digestion. ${ }^{22}$

Table 2 Measurements of cognitive decline in total AD group according to possession of the 84 allele

\begin{tabular}{|c|c|c|c|}
\hline & \multicolumn{2}{|l|}{ Alleles } & \multirow[b]{2}{*}{$P$ values } \\
\hline & $\varepsilon 4-v e$ & $\varepsilon 4+v e$ & \\
\hline $\begin{array}{l}\text { No of patients } \\
\text { Age at onset (y) } \\
\text { Disease duration (y) } \\
\text { MMSE at observation } \\
\text { BDRS at observation }\end{array}$ & $\begin{array}{r}72 \\
78 \cdot 7(7 \cdot 9) \\
4 \cdot 9(4 \cdot 0) \\
11 \cdot 2(6 \cdot 7) \\
7 \cdot 8(3 \cdot 5)\end{array}$ & $\begin{array}{r}92 \\
75 \cdot 5(5 \cdot 9) \\
5 \cdot 4(3 \cdot 3) \\
10 \cdot 3(6 \cdot 9) \\
8 \cdot 3(4 \cdot 3)\end{array}$ & $\begin{array}{l}0 \cdot 004^{\star} \\
0 \cdot 32 \dagger \\
0 \cdot 45^{\star} \\
0 \cdot 73^{\star}\end{array}$ \\
\hline $\begin{array}{l}\text { Progression } \\
\text { MMSE points } \\
\text { BDRS points }\end{array}$ & $\begin{array}{l}2.9(3.4) \\
1.4(2.9)\end{array}$ & $\begin{array}{l}2.3(3.5) \\
0.9(2.8)\end{array}$ & $\begin{array}{l}0 \cdot 40 \ddagger \\
0 \cdot 41 \neq\end{array}$ \\
\hline
\end{tabular}

Values are means (SD).

*Mann-Whitney $U$ tes

tIndependent $t$ test.

$\ddagger$ Analysis of covariance; MMSE decline $F=0 \cdot 36$, BDRS decline $F=0.34$

Initial MMSE $\geqslant 5(\mathrm{n}=47$ and 60 for - and $\varepsilon 4$ patients respectively).

MMSE = mini mental state examination; BDRS = Blessed dementia rating scale.
STATISTICAL ANALYSIS

Comparisons of allele frequencies were made using $\chi^{2}$ and Fisher's exact statistics.

The presence or absence of ApoE $\varepsilon 4$ or ApoE $\varepsilon 2$ alleles and the parametric variable, disease duration at interview, were analysed by the independent $t$ test and the non-parametric variables (age at onset, Cornell score, and the initial cognitive state) by Mann-Whitney $U$ test. Analysis of cognitive decline was by analysis of covariance adjusting for baseline differences in initial MMSE and BDRS scores.

Subcategories of the non-cognitive variables, consisting of the aggregate score of the five composite questions (symptom present $=$ 1 , symptom absent $=0$ ) were analysed according to the presence or absence of the ApoE $\varepsilon 4$ or ApoE $\varepsilon 2$ allele by the MannWhitney $U$ test. All results were corrected for multiple comparisons using the Bonferroni method. ${ }^{23}$

\section{Results}

Table 1 shows the frequencies of alleles among the probable, possible, and total (probable and possible cases combined) Alzheimer's disease groups compared with relatively aged controls from a previous United Kingdom study. ${ }^{24}$ Probable and possible groups did not differ significantly from each other for age at interview, age at onset, duration of illness, sex, family history of Alzheimer's disease, or for either allele. The probable Alzheimer's disease group was significantly higher than the control group for ApoE $\varepsilon 4$ allele frequency $\left(\chi^{2}=\right.$ 15.82 , df $=1, P=0.00007)$ and significantly lower than the control group for ApoE $\varepsilon 2$ frequency $\left(\chi^{2}=12.06, \mathrm{df}=1, \mathrm{P}=0.0005\right)$.

Table 2 shows measurements of cognitive decline in total Alzheimer's disease cases. Possession of the ApoE $\varepsilon 4$ allele was associated with a roughly 3 year earlier age at onset (Mann-Whitney $U$ test, $P=0.004$ ). Analysis of the probable Alzheimer's disease group alone likewise showed a similar trend with a roughly 4 year earlier age at onset (MannWhitney $U$ test, $P=0.001$ ). No association was found between measurements of MMSE, BDRS, or disease duration at initial interview and presence or absence of the ApoE $\varepsilon 4$ allele.

Of the 164 patients from the total Alzheimer's disease group 145 had a one year follow up (13 had died and six relatives had not responded to requests for follow up). Of these cases, 107 had an initial MMSE score greater than or equal to five points (mean initial MMSE 13.0 (SD 5.1). Thirty seven of these patients had had a second yearly follow up at the time of this study. No significant difference was found between measurements of yearly cognitive decline (mean MMSE decline 2.6 (SD.3.5) points per year and BDRS decline $1 \cdot 1$ (SD 2.9) points per year) for either MMSE or BDRS and the presence of the ApoE $\varepsilon 4$ or ApoE $\varepsilon 2$ alleles in the total Alzheimer's disease group adjusting for baseline measurements. Likewise, analysis of the probable Alzheimer's disease group alone failed to show a relation between either pos- 
session of ApoE $\varepsilon 4$ or $\varepsilon 2$ alleles with measurements of cognitive decline.

No significant association was found between the 12 non-cognitive subcategories and ApoE $\varepsilon 4$ gene dosage after Bonferroni correction. Likewise no significant association was found between 11 non-cognitive subcategories and ApoE $\varepsilon 2$ gene dosage. However, the depressive subcategory score, consisting of the aggregate score of the five composite questions pertaining to depressive symptomatology, was significantly associated with the presence of the ApoE $\varepsilon 2$ allele in the total Alzheimer's disease group ( $\mathrm{n}=9$, MannWhitney $U$ test, $P=0.004$ after Bonferroni correction) and in the probable Alzheimer's disease group alone $(n=5$, Mann-Whitney $U$ test, $\mathrm{P}=0.018$ after Bonferonni correction). These subcategories of subjects did not differ significantly from the rest of the Alzheimer's disease group in terms of age at interview, age at onset, duration of illness, sex or family history of Alzheimer's disease.

No relation was found between the Cornell score and ApoE $\varepsilon 4$ gene dosage but higher scores (more depressive symptomatology) were again also related to the presence of the ApoE $\varepsilon 2$ allele in the total Alzheimer's disease group (Mann-Whitney $U$ test, $P=0.026$ ) and in the probable Alzheimer's disease group alone (Mann-Whitney $U$ test, $P=0.029$ ).

\section{Discussion}

This community based study confirms some previous reports of an increased ApoE $\varepsilon 4$ and a decreased ApoE $\varepsilon 2$ allele frequency in subjects with Alzheimer's disease compared with control subjects. ${ }^{12}$ The United Kingdom control group used here ${ }^{24}$ is not ideal in view of their younger age; however, these values should, if anything, underestimate these differences because of the higher ApoE $\varepsilon 4$ allele frequency and lower $A p o E \varepsilon 2$ allele frequency in younger people. ${ }^{25}$

From neuropathological studies postulating a role of ApoE $\varepsilon 4$ in the formation of plaques and tangles, ${ }^{3}$ a positive relation between the presence of the ApoE $\varepsilon 4$ allele and measurements of the rate of cognitive decline might be expected. The present study failed to show such a relation between two different and independent measures of cognitive decline (MMSE and BDRS) and the ApoE $\varepsilon 4$ allele in patients with moderate to severe cognitive deficit at initial interview. Whereas it remains possible that the ApoE $\varepsilon 4$ allele affects progression in the very early stages of the disease process the failure to show a progression in the moderate to severe range of the disease is interesting in that it suggests that ApoE $\varepsilon 4$ is a risk factor for acquiring the disease but not in the subsequent pathological process.

Surprisingly few measures of non-cognitive psychopathology show any relation with ApoE $\varepsilon 4$ or $\varepsilon 2$ allele frequency. In this study the only relation found was between the presence of the ApoE $\varepsilon 2$ allele and depressive symptomatology, which was independent of confounding variables including duration of dementia and sex. Some patients with depressive symptomatology did not carry the ApoE $\varepsilon 2$ gene and so its presence is insufficient to account for all such symptoms in Alzheimer's disease. Although speculative, this association is interesting in view of a possible relation between low serum cholesterol concentrations and depressive symptomatology ${ }^{26}$ and the finding of low serum cholesterol in ApoE $\varepsilon 2$ carrying subjects. $^{27}$ We are indebted to Heather Cadbury, Rachel Pattison, and interviews and blood samples and for the consistent cooperainterviews and blood samples and for the consistent coopera-
tion of all the medical and social agencies supplying information of all the medical and social agencies supplying informa-
tion to the Camberwell Dementia Case Register. David Ball tion to the Camberwell Dementia Case Register. David Ball
and Zinat E Enayat provided valuable technical advice on ApoE genotyping.

This research was supported partly by a Project Grant to Professor R Levy from the Wellcome Trust (Grant No $036000 / 1.5$ ). Funds for laboratory consumables were donated by the Psychiatry research trust.

1 Corder EH, Saunders AM, Strittmatter WJ, Schmechel DE, Gaskell PC, Small GW, et al. Gene dose of apolipoprotein $\mathrm{E}$ type 4 allele and the risk of Alzheimer's disease in late onset families. Science 1993;261:921-3.

2 Kuusisto J, Koivisto K, Kervinen K, Mykkanen L, Helkala $\mathrm{EL}$, Vanhanen $\mathrm{M}$, et al. Association of apolipoprotein $\mathrm{E}$ phenotypes with late onset Alzheimer's disease: population based study. BMF 1994;309:636-8.

3 Ohm TG, Kirca M, Bohl J. Scharnagl H, Gro $\beta$ W, Marz W. Apolipoprotein E polymorphism influences not only cerebral senile plaque load but also Alzheimer-type neucerebral senile plaque load but also Alzheimer-type neu-

rofibrillary tangle formation. Neuroscience 1995;66:583-7.
4 Henderson AS, Easteal S, Jorm AF, Mackinnon AJ, Korten $\mathrm{AE}$, Christensen $\mathrm{H}$, et al. Apolipoprotein E allele e4, dementia and cognitive decline in a population sample. Lancet 1995;346:1387-90.

5 Frisoni GB, Govoni S, Geroldi C, Bianchetti A, Calabresi L, Franceschini G, et al. Gene dose of the e4 allele of apolipoprotein $\mathrm{E}$ and disease progression in sporadic late-onset Alzheimer's disease. Ann Neurol 1995;37: 596-604.

6 Basun H, Grut M, Lannfelt L. Apolipoprotein e4 allele and disease progression in patients with late-onset Alzheimer's disease. Neurosci Lett 1995;183:32-4.

7 American Psychiatric Association. Diagnostic and statistical manual of mental disorders. 3rd ed, revised (DSM-III-R). Washington, DC: APA, 1987;103-7.

8 The International Classification of Diseases Volume 10. Classification of mental and behavioural disorders. Geneva: World Health Organisation; 1992;45-6.

9 McKhann G, Drachman D, Folstein M, Katzman R, Price D, Stadian EM. Clinical diagnosis of Alzheimer's disease: report of the NINCDS-ADRDA Work Group. Neurology 1984;34:939-44

10 Steele C, Rouner B, Chase GA, Folstein M. Psychiatric symptoms and nursing home placements of patients with Alzheimer's disease. Am $\mathcal{f}$ Psychiatry 1990;147:1048-51.

11 Holmes C, Cooper B, Levy R. Dementia known to mental health services: first findings of a case register for a defined elderly population International fournal of Geriatric Psychiatry 1995;10:875-81.

12 Holmes $C$. The Camberwell dementia case register. International fournal of Geriatric Psychiatry 1996;11: Internationa

13 Mölsa PK, Marttila, RJ, Rinne UK. Epidemiology of dementia in a Finnish population. Acta Neurol Scand dementia in a Finn
$1982 ; 65: 541-552$.

14 Kokmen, E, Chandra V, Schoenberg, BS. Trends in incidence of dementing illness in Rochester, Minnesota, in three quinquennial periods, 1960-1974. Neurology 1988; 38:975-80.

15 Roth M, Huppert FA, Tym E, Mountioy CQ. CAMDEX: the Cambridge examination for mental disorders of the elderly. Cambridge, UK: Cambridge University Press, 1988.

16 Hope T, Fairburn CG. The Present behavioural examination (PBE): the development of an interview to measure current behavioural abnormalities. Psychol Med 1992;22: 223-30.

17 Meer B, Baker JA. The Stockton geriatric rating scale. $\mathcal{f}$ Gerontol 1966;21:392-403.

18 Folstein MF, Folstein SE, McHugh PR. Mini-mental state: a practical method for grading the cognitive state of a practical method for grading the cognitive state of
patients for the clinician. $\mathcal{F}$ Psychiatr Res $1975 ; 12$ :189-98.

19 patients for the clinician. F Psychiatr Res 1975;12:189-98. between quantitative measures of dementia and senile change in the cerebral grey matter of elderly subjects. $\mathrm{Br} F$ Psychiatry 1968;114:797-811.

20 Becker JT, Huff FJ, Nebes RD, Holland A, Boller F. Neuropsychological function in Alzheimer's disease: pattern of impairment and rates of progression. Arch Neurol 1984;45:263-8.

21 Alexopoulos GS, Abrams RC, Young RC, Shamoian CA. Cornell scale for depression in dementia. Biol Psychiatry 1988;23:271-84. 
22 Wenham PR, Price WH, Blundell, G. Apolipoprotein E genotyping by one-stage PCR. Lancet 1991;337: 1158-9.

23 Savitz DA, Olshan AO. Multiple comparisons and related issues in the interpretation of epidemiologic data. $A m \mathcal{F}$ Epidemiol 1995;142:204-8.

24 Liddell $M$, Williams J, Bayer A, Kaiser F, Owen $M$. Confirmation of association between the e4 allele of apolipoprotein $\mathrm{E}$ and Alzheimer's disease. $7 \mathrm{Med}$ Genet 1994;31:197-200.
25 Schächter F, Faure-Delanef L, Guénot F, Herve R, Froguel P, Leseur-Ginot L, et al. Genetic associations with human longevity at the APOE and ACE loci. Nature Genet 1994;6:29-32.

26 Morgan RS, Palinkas LA, Barrett-Connor EL, Wingard DL. Plasma cholesterol and depressive symptoms in older men. Lancet 1993;341:75-9.

27 Utermann G, Steinmetz A. Polymorphism of apolipoprotein $\mathbf{E}$ and occurrence of dybetalipoproteinaemia in man Nature 1977;269:604-7. 